\title{
Leitura Compartilhada - A melhor leitura é aquela que se compartilha
}

\author{
Deivid Souza $^{1}$, Flávia Sayane ${ }^{1}$, Laine Cardoso ${ }^{1}$, Luciano Pinheiro ${ }^{1}$, \\ Sahid Sousa $^{1}$ Carlos Hugo Lopes $^{1}$, Muller Miranda ${ }^{1}$, Fábio Bezerra ${ }^{1}$ \\ ${ }^{1}$ Instituto Ciberespacial - Universidade Federal Rural da Amazônia (UFRA) \\ Avenida Presidente Tancredo Neves, 2501 - Belém-Pará \\ \{muller.miranda, fabio.bezerra\}@ufra.edu.br
}

\begin{abstract}
Resumo. O Leitura Compartilhada é uma plataforma gratuita de inventário e compartilhamento de livros físicos entre amigos e parentes. Permite que leitores conheçam os livros uns dos outros, bem como criem comunidades de leitura, doem ou emprestem seus livros. Assim, podemos dizer que essa moderna plataforma funciona como uma biblioteca distribuída, uma vez que os livros estão espalhados entre os leitores, que estão em diferentes locais do mundo. Ademais, dizemos que é uma rede social cujo elo entre os leitores são os livros, uma fonte de conhecimento e instrumento para conhecer novas pessoas, tendências literárias e trocar experiências de leitura.
\end{abstract}

\begin{abstract}
Leitura Compartilhada is a free platform for inventorying and sharing physical books between friends and relatives. It allows readers to know each other's books, as well as to create reading communities. Therefore, we can say that this modern platform works like a distributed library, since the books are spread among the readers, who are in different places of the world. Moreover, we say that it is a social network whose link between readers is books, a source of knowledge and a way to meet new people, literary trends and exchange reading experiences.
\end{abstract}

\section{Cenário de Uso}

O Leitura Compartilhada (http://leituracompartilhada.com.br/) é uma plataforma on-line de compartilhamento de livros físicos, também disponível como aplicativo para a plataforma Android, que ajudará leitores a emprestar livros uns aos outros. Porque auxilia na exposição dos livros e gestão dos empréstimo, acreditamos que a plataforma ampliará o uso da capacidade excedente de conhecimento que estava "armazenada" na estante de sua casa ou local de trabalho, acumulando poeira e ácaros.

A ideia da plataforma surgiu a partir da observação que um dos fundadores da plataforma fez de sua filha, quando ainda possuía 11 anos, que emprestava e pegava emprestado livros com um grupo de outras meninas da escola. Então ele pensou que aquela troca de livros deveria ser gerenciada, para garantir o controle de quem está com os livros, mas principalmente estimulada em sala de aula a partir dos professores. No caso, o professor seria o fundador do grupo (turma), curador da seleção de livros, pois apresentaria uma lista de títulos que cada aluno se comprometeria a adquirir um, e mediador do processo de empréstimo entre os alunos. Portanto, a plataforma seria um excelente instrumento: i) de gestão da troca de livros entre os alunos; ii) auxiliar do professor no 
acompanhamento das leituras que cada aluno realizava; e principalmente iii) um auxiliar na promoção do hábito da leitura.

No entanto, projetando e discutindo sobre a plataforma com várias pessoas, notamos que o Leitura Compartilhada não precisaria se limitar ao escopo de uma turma ou grupo de alunos de uma escola, mas a qualquer pessoa no mundo. No caso, o livro funcionaria como um elo de aproximação das pessoas, pois elas teriam a oportunidade de conhecer os livros umas das outras, mas também as pessoas seriam as multiplicadoras do conhecimento, quando estimuladas a empresar seus livros, uma vez que o sistema permite o rastreio e controle dessa operação de empréstimo, aumentando a segurança para aquele que empresta seu livro a um leitor.

Para ilustrar mais a ideia da plataforma, considere aquele livro que você comprou ou ganhou, acabou de ler e foi para estante de sua casa ou local de trabalho. Dizemos que esse livro é uma capacidade excedente[Robin Chase 2015, Gansky 2012] de conhecimento, pois poderia ser emprestado a um amigo ou familiar. No entanto, dificilmente o será, pois nenhum deles (seus amigos ou parentes) sabem que você possui esse livro (ou dificilmente saberia), que o livro é interessante e que você estaria disposto a emprestálo. O Leitura Compartilhada é exatamente a plataforma que permitirá o acesso a essa capacidade excedente, ou seja, os livros.

De acordo com a pesquisa realizada pelo IBGE, intitulada "Retratos da Leitura no Brasil'"[Failla 2016], duas das principais barreiras para o hábito da leitura são: Inexistência de bibliotecas próximas aos leitores e alto custo financeiro para aquisição de novos livros. A pesquisa ouviu 5.012 pessoas. Isso representa, segundo o Ibope, $93 \%$ da população brasileira. Portanto, não é absurdo inferir que o compartilhamento de livros apresenta-se como uma excelente prática para o fomento da leitura, uma vez que tais barreiras (bibliotecas e preço do livro) poderão ser minimizadas.

\section{Desenvolvimento}

A plataforma Leitura Compartilhada está fundamentada no conceito de economia compartilhada, cuja visão geral da aderência da plataforma a este conceito apresentamos na Seção 2.1. O projeto foi desenvolvido com a linguagem Java para Web, cuja arquitetura e processo de desenvolvimento estão descritos na Seção 2.2.

O lançamento do Leitura Compartilhada aconteceu durante a XXI Feira PanAmazônica do Livro ${ }^{1}$, que aconteceu de 26 de maio a 04 de junho. Portanto, trata-se de uma plataforma recentemente apresentada à comunidade, mas que já recebeu, durante a exposição na feira, bastante retorno dos visitantes. A avaliação da ideia e das funcionalidades propostas para a plataforma durante a feira estão relatadas na Seção 2.3.

\subsection{Fundamentação}

De acordo com Robin Chase, co-fundadora da Zip Car², em seu livro [Robin Chase 2015], a economia compartilhada está apoiada em três elementos constitutivos: i) capacidade excedente, que permite ver abundância em um mundo de escassez; ii) plataformas de participação, que ajuda na simplificação, organização e capacitação do acesso a essa

\footnotetext{
${ }^{1}$ http://www. feiradolivro.pa.gov.br/home

${ }^{2}$ A http: / / www. zipcar.com/ é uma plataforma de compartilhamento de carros
} 
VI Congresso Brasileiro de Informática na Educação (CBIE 2017)

Anais dos Workshops do VI Congresso Brasileiro de Informática na Educação (WCBIE 2017)

capacidade excedente; e iii) o poder dos peers, no caso, as pessoas que atuam na plataforma, adaptando o uso para o contexto local, customizando e especializando o conteúdo da capacidade excedente.

No caso do Leitura Compartilhada, a capacidade excedente são aqueles livros que estão nas estantes de sua casa ou trabalho, inacessíveis para muitos de seus amigos e parentes, porque eles não sabem que você os possui e que estaria disposto a emprestarlhes (ou mesmo doar). Disponibilizar essa lista enorme de livros para seus amigos seria extremamente difícil, ou mesmo, impossível, sem uma plataforma de compartilhamento, com ferramentas de busca, inventário e integração das pessoas que a compõe. Finalmente, sem as pessoas acessando e compartilhando seus livros, definindo tendências de leitura e conhecendo os hábitos literários de seus amigos, toda essa capacidade excedente não poderia ser acessada.

Quanto a capacidade excedente dos livros na plataforma, vale destacar que sozinha não passa de um valor em potencial, pois o valor real resulta de sua leitura. Ademais, o custo de acesso a um livro pela plataforma é muito reduzido, pois já foi pago por quem está emprestando.

\subsection{Arquitetura do Sistema}

A arquitetura da aplicação, esquematicamente representada na Figura 1, é multicamadas, ou seja, camadas superiores acessam os serviços de camadas inferiores, mas camadas inferiores não conhecem ou acessam as camadas superiores.

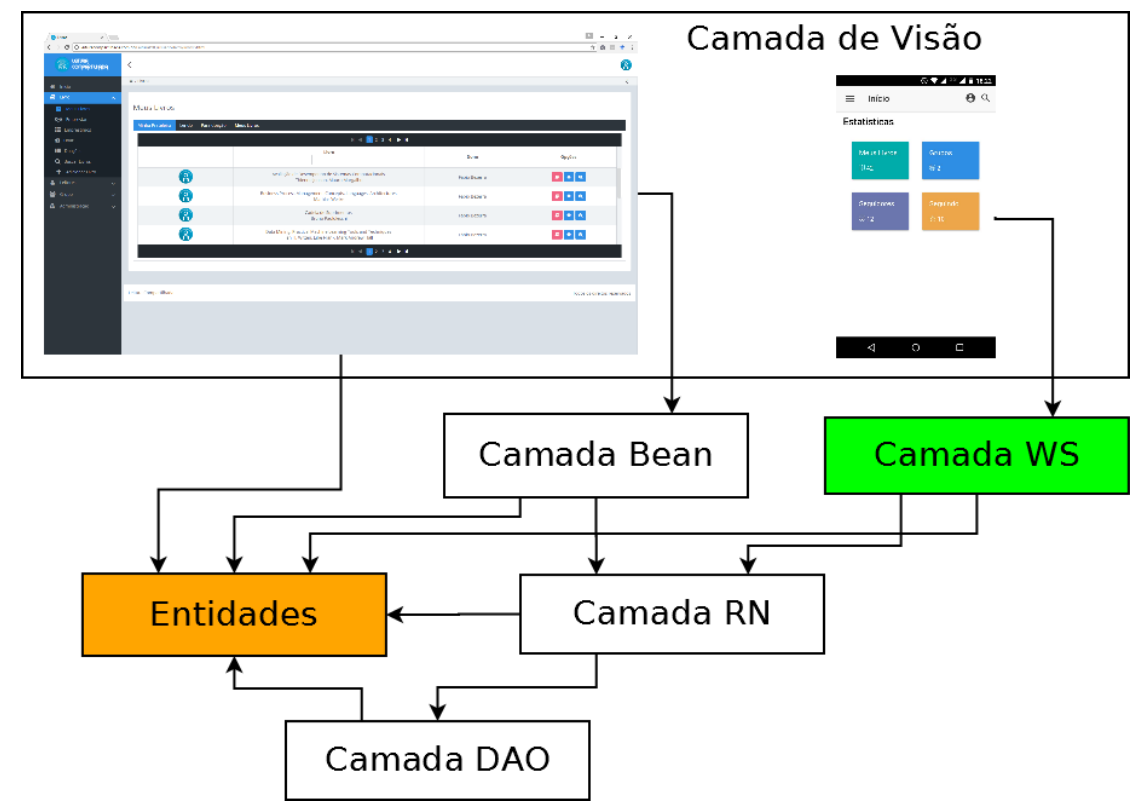

Figura 1. Visão geral da arquitetua do sistema.

A aplicação está disponível para os leitores como um sistema web, que pode ser utilizada em um computador pessoal, mas também em navegadores de dispositivos móveis, pois o sistema Web é totalmente responsivo. No caso, adotamos: i) o framework Java Server Faces (JSF)[Luckow and de Melo 2010], que é uma implementação MVC 
(Model-View-Controller) da camada de visão da aplicação; e ii) a biblioteca de componentes visuais Primefaces ${ }^{3}$. Na arquitetura, o sistema web aparece na Camada Visão.

Porque a aplicação foi construída com o framework JSF, podemos observar na Figura 1 a Camada Bean. Esta camada contém as classes de Bean Gerenciável (Managed Bean), ou seja, que promovem: i) interceptação dos eventos de interação com o usuário nas páginas Web; ii) trânsito (entrada e saída) dos objetos que serão apresentados nas páginas Web; iii) navegação entre as páginas da aplicação; mas principalmente, iv) o papel de controle na arquitetura MVC.

Além do sistema Web, há também um aplicativo, disponível apenas para o ecossistema Android, que é o ecossistema de software mais popular e disponível e utilizado em diferentes plataformas e equipamentos. Por outro lado, vale observar que apesar do aplicativo estar disponível apenas para Android, o mesmo foi construído utilizando Ionic ${ }^{4}$, pois no futuro pretendemos disponibilizar a mesma aplicação também para o ecossistema iOS. Assim, no caso do aplicativo mobile, as tecnologias envolvidas em seu desenvolvimento são: HTML5, CSS3, Javascript e AngularJS.

$\mathrm{Na}$ arquitetura, o aplicativo aparece na Camada Visão, mas é integrado ao restante do sistema a partir da Camada WS, de Web Services, tornando o aplicativo um Thin Client (cliente magro). No caso, a Camada WS mantém as classes que implementam serviços RESTful de acesso a vários recursos do sistema, como por exemplo, login e estatísticas (ex: livros, empréstimos, seguidores).

A Camada Entidades mantém as classes que descrevem o negócio ou núcleo da aplicação, ou seja, são as classes conceituais da aplicação (ex: Livro, Cópia, Usuário, Empréstimo, etc.), pois descrevem quais dados são manipulados pela aplicação. Por essa razão, os objetos dessa camada são acessíveis por todas as outras camadas da aplicação: Visão, Bean, WS, RN e DAO. Note que a Camada Entidades é altamente coesa e fracamente acoplada.

Enquanto a Camada Entidades é considerada o núcleo da aplicação, quando observamos as classes conceituais. Dizemos que a Camada RN (Regra de Negócios) mantém as classes responsáveis pela inteligência da aplicação, onde são implementadas as regras de negócios da aplicação. Por outro lado, diferente da Camada Entidades, essa camada não é totalmente desacoplada do restante do sistema.

A persistência dos dados e seu acesso foi implementada na Camada DAO, acrônimo para Data Access Object, utilizando o Framework Java Persistence API (JPA)[Luckow and de Melo 2010], que é um meio de mapeamento objeto-relacional para objetos Java simples e comuns, denominados de entidade. O banco de dados utilizado é o MySQL ${ }^{5}$, que é um banco de dados bastante popular tanto na indústria como no meio acadêmico, conhecido por sua facilidade de uso e gratuitamente disponível.

\footnotetext{
${ }^{3}$ Disponível em https: //www.primefaces.org/, oferta diferentes templates e layouts de componentes visuais, alguns gratuitos e outros pagos.

${ }^{4}$ O Framework Ionic, disponível em http: // ionicframework.com/, é um Software Development Kit para desenvolvimento de aplicações híbridas para dispositivos móveis, de rápido e fácil desenvolvimento.

${ }^{5} \mathrm{O}$ https : / / www mysql. com/ possui versões gratuitas e pagas para diversas plataformas
} 
VI Congresso Brasileiro de Informática na Educação (CBIE 2017)

Anais dos Workshops do VI Congresso Brasileiro de Informática na Educação (WCBIE 2017)

\subsection{Questionário de Avaliação}

O Leitura Compartilhada foi lançado durante a Feira Pan-Amazônica do Livro, que é a quarta maior feira de literatura do Brasil e a maior da Região Norte em termos de programação e área ocupada ${ }^{6}$. Realizado anualmente, o evento conta com público estimado de 400 mil visitantes interessados na leitura, por essa razão decidimos avaliar a ideia da plataforma com esse público.

O questionário aplicado foi respondido por 104 pessoas. No caso, estávamos interessados em identificar o hábito de leitura, a disponibilidade do leitor em emprestar seu livros e como avaliaria algumas funcionalidades do sistema, a citar: grupos de leitura, conhecer os livros de outros leitores e gerenciamento do empréstimo de um livro.

Quanto ao perfil dos respondentes, 53\% são jovens entre 18 e 25 anos de idade. Ademais, dos 104 respondentes, 52.9\% são homens e 47.1\% são mulheres. Quando perguntados se tem dificuldade para comprar um livro, $40 \%$ responderam que possuem alguma dificuldade.

Quanto a quantidade de livros que possuem e a disponibilidade em emprestar seus livros a outras pessoas, observamos que há uma capacidade excedente muito grande de livros. No caso, mais da metade dos respondente possuem mais de 30 livros e mais da metade dos respondentes emprestaria pelo menos $50 \%$ de seus livros. Enquanto, $25 \%$ dos respondentes estariam dispostos a emprestar todos os livros que possuem.

Também observamos nas entrevistas que os leitores estão muito propensos a emprestar seus livros, desde que o destinatário seja um amigo ou familiar. No caso, quando questionados se concordam com a frase "Eu não vejo problema em emprestar um livro há um amigo", $76 \%$ responderam que concordam totalmente e $23 \%$ responderam que concordam em parte; quando questionados se concordam com a frase "Eu não vejo problema em emprestar um livro há um familiar", $79 \%$ responderam que concordam totalmente e $18 \%$ responderam que concordam em parte. Esse resultado reforça a nossa hipótese de que as pessoas estão dispostas a compartilhar seus livros.

Nesse sentido, o Leitura Compartilhada apresenta-se como um excelente instrumento de acesso a esses livros, pois tornará público, a outros leitores, quais livros possui e está disposto a emprestar. Vale lembrar que adicionar os livros na plataforma não significa que o leitor está obrigado a emprestá-lo, até porque a operação de empréstimo é realizada pessoalmente.

Finalmente, observamos que a aceitação do projeto foi excelente, pois $99 \%$ responderam que consideram a ideia boa ou excelente $(62.5 \%$ excelente, $36.5 \%$ bom, $1 \%$ regular e $0 \%$ ruim). Ademais, em uma escala de 1 a 5, onde 1 significa "Pouco interessante" e 5 "Muito interessante", obtivemos os seguintes resultados:

- Para a pergunta "O que você acha de uma ferramenta que lhe ajudasse a controlar os livros que você emprestou a alguém?": 71.2\% responderam 5 para a pergunta; $\mathbf{2 2 . 1 \%}$ responderam 4 para a pergunta.

- Para a pergunta "O que você acha de uma ferramenta que lhe ajudasse a conhecer os livros que seu amigo está disposto a emprestar?":84.6\% responderam 5 para a pergunta; $\mathbf{1 0 . 6 \%}$ responderam 4 para a pergunta.

\footnotetext{
${ }^{6}$ Fonte MinC - https://goo.gl/XBJncG
} 
VI Congresso Brasileiro de Informática na Educação (CBIE 2017)

Anais dos Workshops do VI Congresso Brasileiro de Informática na Educação (WCBIE 2017)

Portanto, observando as resposta, há claramente uma disponibilidade dos leitores em emprestar seus livros e utilizar uma ferramente que lhes ajude a controlar quem pegou emprestado seus livros, bem como conhecer os livros que seus amigos e familiares possuem e estão dispostos a emprestar.

\section{Apresentação do Software}

Acessível no endereço eletrônico http:// leituracompartilhada.com.br/, após a criação e validação da conta, que ocorre a partir da confirmação via e-mail, o leitor poderá fazer o inventário de seus livros (Seção 3.1), emprestar ou doar livros a outros leitores da plataforma (Seção 3.2), seguir ou ser seguido por outros leitores e criar grupos ou comunidades de leitores que possuem confiança uns nos outros para emprestar seus livros (Seção 3.3). Uma apresentação geral do Leitura Compartilhada pode ser vista no vídeo disponível em https : / / youtu . be /FxSWP 89 Jn9 I

\subsection{Inventário dos Meus Livros}

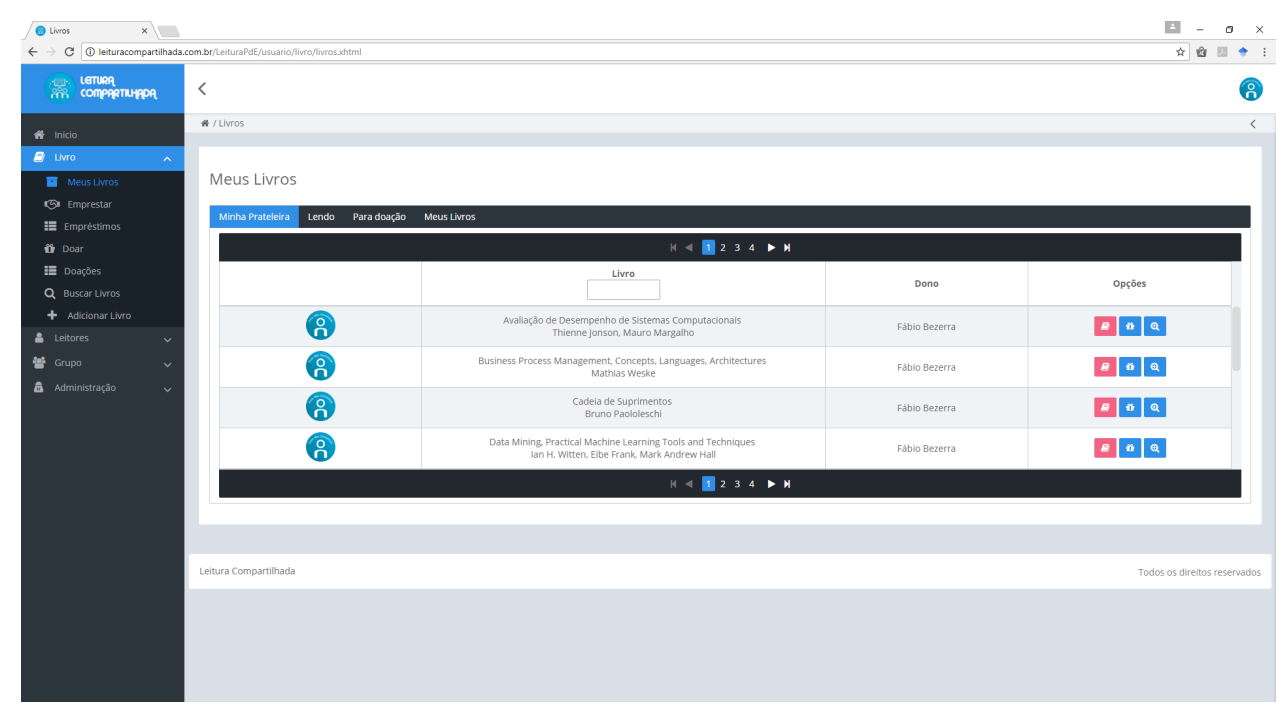

Figura 2. Prateleira virtual dos meus livros físicos.

O inventário dos livros é o ponto de partida para o leitor começar a compartilhar seus livros e expô-los a amigos e familiares. Durante o cadastro, um livro pode ser facilmente recuperado a partir da digitação do número ISBN International Standard Book Number, pois há uma integração com a API Google Books. Na Figura 2 ilustramos como o leitor visualiza os livros que mantém posse, está lendo, reservou para doação e é dono.

\subsection{Empréstimo e Doação de Livro}

Apesar da história de criação da plataforma ter nascido a partir do empréstimo de livros, observamos a partir de comentários e sugestões de várias pessoas, que muitos leitores compram o livro e aceitam se desfazer do mesmo porque não tem como armazenar. Assim, a plataforma permite que o leitor não apenas empreste, mas também doe seus livros.

As operações de empréstimo e doação são bem semelhantes, pois ambas exigem os seguintes passos para se completar: i) localizar e selecionar o leitor que receberá o livro; ii) localizar e selecionar os livros que serão entregues ao leitor selecionado; iii) o 
VI Congresso Brasileiro de Informática na Educação (CBIE 2017)

Anais dos Workshops do VI Congresso Brasileiro de Informática na Educação (WCBIE 2017)

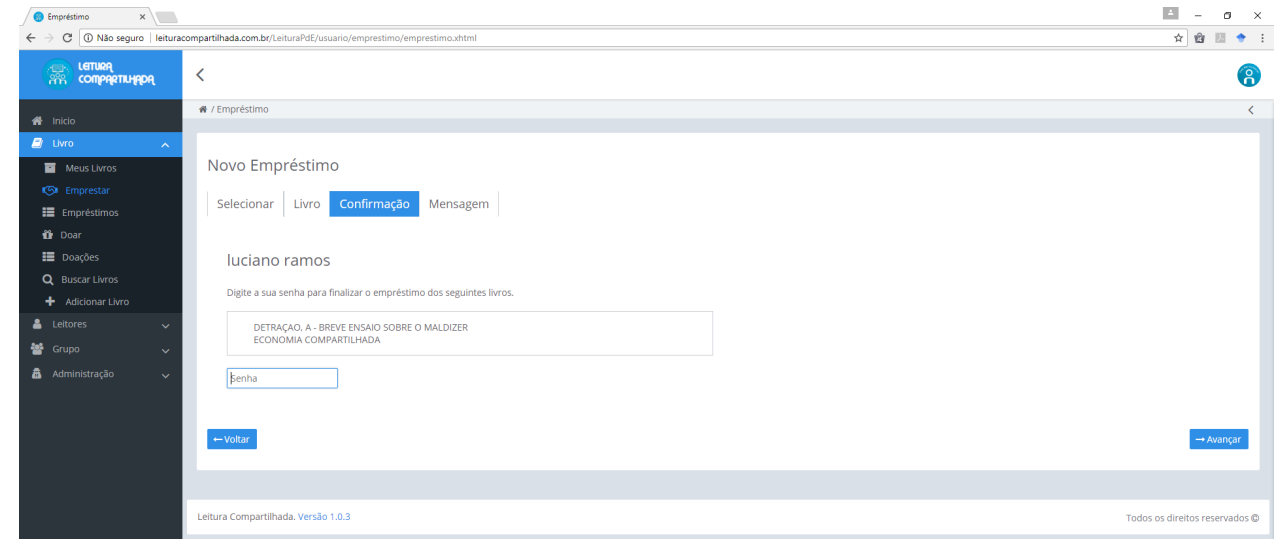

Figura 3. Confirmando o empréstimo com a senha.

leitor que receberá os livros confirmará com sua senha o recebimento dos livros (Figura 3); finalmente, iv) uma mensagem de confirmação da operação será apresentada ao leitor. Vale destacar que todos esses passos são realizados na sessão de uso do leitor que está emprestando ou doando o livro.

No empréstimo ou doação, destacamos o terceiro passo, quando o leitor que receberá o livro terá que confirmar o recebimento com sua senha de acesso a plataforma. Dessa forma, aumentamos a segurança do procedimento de empréstimo (ou doação), uma vez que o receptor do livro "assina", na sessão do leitor que está emprestando os livros, que recebeu os livros emprestados, ao digitar a senha de acesso à plataforma.

\subsection{Rede Social e Grupos de Leituras}

Dizemos que o Leitura Compartilhada é uma rede social porque as pessoas se conectam por causa dos livros - fisicamente para emprestar ou doar um livro ou virtualmente para conhecer umas as outras (livros e perfil) - e formam grupos de leitores. No caso, os grupos significam mais que comunidades que compartilham a mesma preferência de leitura, pois pertencer a um grupo significa confiar em todos os outros membros. Por isso consideramos que a ferramenta de grupos pode ser um instrumento de mediação do professor em sala de aula com uma turma, ou mesmo um conjunto de turmas, desde que no mesmo grupo.

Para entender o que são os grupos na plataforma, considere que João, Maria e José são de um mesmo grupo. Nesse caso, José pode emprestar de Maria os livros que Maria mantém em sua prateleira e que pegou do João, que é o dono dos livros. Portanto, como José, Maria e João estão no mesmo grupo, José não precisa esperar a Maria devolver o livro a João para pegá-lo emprestado. Assim, desburocratizar o ciclo de empréstimos é o que chamamos de ciclo de leitura, cenário esperado tanto em uma turma da escola ou faculdade, como em um grupo de pesquisa ou de amigos. Por isso dizemos que os grupos são mais uma ferramenta onde o professor ou líder técnico pode desenvolver atividades de estímulo e promoção da leitura e compartilhamento de conhecimento.

\section{Considerações Finais}

Neste trabalho apresentamos o projeto Leitura Compartilhada, que apesar de jovem, pois foi lançado no final de maio deste ano, já é uma plataforma rica em recursos e bem aceita 
VI Congresso Brasileiro de Informática na Educação (CBIE 2017)

Anais dos Workshops do VI Congresso Brasileiro de Informática na Educação (WCBIE 2017)

pelo público, que enxerga nessa ferramenta um instrumento de promoção do hábito da leitura. Entre as funcionalidades que podemos destacar:

Inventário registro pessoal dos livros e exposição para outros leitores conhecerem os livros que possuo

Grupos os grupos de leitores não apenas podem ser utilizados para definir interesse comum de leitura, mas também confiança no empréstimos de livros entre os membros, uma vez que não preciso devolver o livro ao dono para emprestá-lo a outro membro do grupo se o dono também é membro do mesmo grupo

Rede Social visitar o perfil de um leitor, conhecer as pessoas que me seguem e seguir outros leitores

Durante o lançamento do sistema, que aconteceu na XXI Feira Pan-Amazônica do Livro, realizamos 104 entrevistar com leitores e, portanto, potenciais usuários da plataforma. Considerando essa entrevista, podemos dizer que houve uma clara aprovação dos entrevistados, que avaliaram, em sua maioria, a ideia como excelente. Além disso, especificamente pudemos constatar que há uma inclinação das pessoas em emprestar seus livros a amigos e familiares (em alguns casos até a desconhecidos), o que suporta ainda mais a ideia do projeto.

Reconhecemos que sem leitores e livros a plataforma dificilmente será uma tendência. Por essa razão, estamos trabalhando para intensificar a divulgação do Leitura Compartilhada, especialmente dentro das universidades, por exemplo, através do compartilhamento de livros técnicos. Porém, porque a plataforma está restrita a pessoas com 16 ou mais anos, vamos trabalhar também na divulgação da ideia entre jovens do ensino médio, possibilitando dessa forma criar o que denominamos de ciclo de leitura.

Também planejamos inserir elementos de gamification (estratégia lúdica de interação entre pessoas com base no oferecimento de incentivos que impulsionem a participação) para recompensar aqueles que contribuem mais ou que participam de forma mais ativa na plataforma. Acreditamos que tais elementos podem promover maior engajamento dos leitores, por exemplo, quanto mais ler e compartilhar, mais pontos o leitor irá acumular. Assim, a plataforma poderá exibir um ranking para apresentar os vencedores, potencializando o estímulo da leitura a partir de competições.

\section{Referências}

Failla, Z. (2016). Retratos da leitura no Brasil 4. Sextante, 1 edition.

Gansky, L. (2012). Mesh. Porque O Futuro Dos Negócios É Compartilhar. Alta Books.

Luckow, D. and de Melo, A. (2010). Programação Java para a Web:. NOVATEC, 1 edition.

Robin Chase, C. Y. (2015). Economia Compartilhada. HSM EDITORA, 1 edition. 